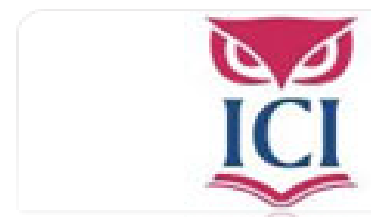

IUS. Revista del Instituto de Ciencias Jurídicas de Puebla A.C.

\title{
ISSN: 1870-2147
}

revista.ius@hotmail.com

Instituto de Ciencias Jurídicas de Puebla A. C.

México

Portilla Contreras, Guillermo

Bases teóricas del "nuevo" derecho penal schmittiano: el derecho penal y procesal penal del "enemigo"

IUS. Revista del Instituto de Ciencias Jurídicas de Puebla A.C., núm. 19, 2007, pp. 23-45 Instituto de Ciencias Jurídicas de Puebla A. C.

Puebla, México 


\section{BASES TEÓRICAS DEL "NUEVO" DERECHO PENAL SCHMITTIANO: EL DERECHO PENAL Y PROCESAL PENAL DEL "ENEMIGO"}

Guillermo Portilla Contreras*

\section{RESUMEN}

El derecho penal de la posmodernidad exhibe simultáneamente dos caras opuestas. En una de ellas, el sujeto sólo responde por la lesión del valor tutelado, la pena adquiere funciones preventivas y no se interrumpen las garantías constitucionales. En la otra, por el contrario, el sujeto aparece como emanación de peligro, como un riesgo potencial para la seguridad del Estado. Es el reingreso de la guerra justa y preventiva como paradigma del nuevo sistema penal. Hablamos entonces de un singular derecho penal de excepción cuyo fin es combatir futuras amenazas, y que restringe garantías fundamentales por su supuesta traba a la razón de Estado.

En estos momentos de la historia está renaciendo la imagen del "monstruo moral" adscrita, como recuerda Foucault a aquellos criminales y anarquistas que, en la segunda mitad del siglo XIX, rechazaban el pacto social; ${ }^{1}$ en efecto, hoy día vuelven a esbozarse parecidas interrogantes con relación a "terroristas" e inmigrantes "ilegales". ¿Deben aplicárseles las mismas leyes al tratarse de enemigos de la sociedad entera? Al no aceptar el contrato social, ¿no quedan al margen de las leyes sociales? ¿No habría que excluirlos del sistema jurídico garantístico ${ }^{2}$

Lo normal en el presente es la conversión del derecho penal en un derecho de autor en el que se acaba confundiendo al enemigo con las "clases peligrosas”, la guerra con la actuación policial, las relaciones internacionales con la política interior. En ese desconcierto entre las finalidades represivas y policiales se relativizan los principios de culpabilidad, propor-

\footnotetext{
* Catedrático de derecho penal en la Universidad de Jaén y de filosofía del derecho y de teoría general del derecho en la Universidad de Camerino. Coordinador de esta entrega junto con el Mtro. Daniel Y. Pérez legón.

${ }^{1}$ Cfr. M. Foucault, "Clase de 29 de enero de 1975", en Los anormales, 2001, p. 93.

${ }^{2}$ Cfr. M. Foucault, Op. cit., p. 93.
} 
cionalidad, y del hecho, a través de una perspectiva orientada al autor en la que desaparecen las garantías procesales. ${ }^{3}$

Con todo, esta categoría limitadora no supone novedad alguna, ha sido el método más habitual en la represión de determinado grupo de delitos; así, el sistema procesal-penal contra la criminalidad organizada se viene caracterizando por una constante restricción de los principios básicos que rigen el tradicional funcionamiento tanto del derecho penal como del derecho procesal penal, hasta el punto de conformar un derecho penalprocesal "distinto". Lo sorprendente no es, por tanto, la existencia de esa legislación y la constante anulación de garantías para los afectados por ella, sino la aparición de un sustento doctrinal que avala -no sólo reconoce- la existencia de un derecho garantístico para personas y otro, sin los clásicos derechos, para las no-personas.

En los últimos años, se observa una acentuada tendencia que, basándose en el modelo del "enemigo", en una legislación de guerra, intenta legitimar la estructura de un derecho penal y procesal sin garantías, la flexibilización de los principios procesales, aquéllos, de corte liberal, que han contribuido a la defensa de la persona: el principio de presunción de inocencia, el fundamento de un proceso legal, el principio nemo-tenetur, el derecho a un proceso justo, etcétera. ${ }^{4}$

Uno de los principales protagonistas en la discusión, G. Jakobs, defiende, bajo la óptica estructural-funcionalista, un sistema que descansa en la contraposición de un derecho para ciudadanos frente a un derecho para enemigos. ${ }^{5}$ Se trata de una construcción que aparece esbozada en un trabajo del autor en $1985,{ }^{6}$ en la que admitía sólo excepcionalmente un de-

${ }^{3}$ Cfr. L. Khulen, "El derecho penal del futuro", en Crítica y justificación del derecho penal en el cambio de siglo, 2003, pp. 225-229.

${ }^{4}$ Vid. H. Schneider, "Bellum Justum gegen den Feind im Inneren?", ZStW, no 3, 2001, pp. 501-502. En el sentido criticado en el texto, Jakobs se ha planteado la interrogante de si puede conducirse una guerra contra el terrorismo con los medios de un derecho penal propio de un estado de derecho. Su respuesta es contundente, un estado de derecho no puede responder adecuadamente a esos riesgos porque ello le obligaria a tratar a sus enemigos como personas y no como fuentes de peligro. Por esa razón, este autor aboga, como veremos más adelante, no por un estado de derecho perfecto sino por un estado de derecho óptimo en la práctica, esto es, un Estado que tenga la posibilidad de no quebrarse por los ataques de sus enemigos a los que retira la condición de personas. Cfr. "¿Terroristas como personas en derecho?”, en Derecho penal del enemigo, Trad. de M. Cancio Meliá, 2006, p. 83.

${ }^{5}$ Vid. G. Jakobs, "Das Selbstverständnis der Strafrechtswissenschaft vor den Herausforderungen der Gegenwart”, en Die deutsche Strafrechtswissenschaft vor der Jahrtausendwende. Rückbesinnung und Ausblick, 2000, pp. 51-52 ("La autocomprensión de la ciencia del derecho penal ante los desafíos del presente”, en La ciencia del derecho penal ante el nuevo milenio, 2004, pp. 57-61).

${ }^{6}$ Cfr. G. Jakobs, "Kriminalisierung in Vorfeld einer Rechtsgutverletzung", en ZStW, 1985, pp. 751-785 (“Criminalización en el estadio previo a la lesión de un bien jurídico", en Estudios de derecho penal, 1997). 
recho penal de enemigos y en una legislación de emergencia, ${ }^{7}$ construcción que experimenta posteriormente un cambio cualitativo cuando reconoce la necesidad de su implantación que ahora convierte en regla, pues no existen alternativas a un modelo penal y procesal funcionalista que prime la defensa de la seguridad del Estado y la ausencia de principios liberales. ${ }^{8}$ No obstante, Jakobs ha expresado su sorpresa y malestar ante las críticas que ha recibido su planteamiento por parte de un sector doctrinal, en el que me incluyo, cuando juzga que, en realidad, lo que se está haciendo con tales censuras es "matar al mensajero" (un calificativo que se aplica a sí mismo) por expresar simplemente un diagnóstico. ${ }^{9}$ Tras la aparición

\footnotetext{
${ }^{7}$ Se refiere, sobre todo, al empleo de la criminalización de estadios previos a la lesión de bienes jurídicos y la penalización de la esfera interna-privada del sujeto, algunos delitos contra la seguridad del Estado o las asociaciones criminales o terroristas. "[...] un derecho penal de índole peculiar que se diferencia nítidamente del derecho penal de ciudadanos: el derecho penal de enemigos optimiza la protección de bienes jurídicos, el derecho penal de ciudadanos optimiza las esferas de libertad". Cfr. G. Jakobs, "Criminalización en el estadio previo a la lesión de un bien jurídico”, Op. cit., pp. 296-298. Contrastando la figura del ciudadano y la del enemigo, afirma: "La existencia de un derecho penal de enemigos no es signo, por tanto, de la fortaleza del estado de libertades, sino un signo de que en esa medida simplemente no existe. Ciertamente, son posibles situaciones, que quizá se dan incluso en este momento, en que las normas imprescindibles para un estado de libertades pierden su poder de vigencia si se aguarda con la represión hasta que el autor salga de su esfera privada. Pero incluso entonces el derecho penal de enemigos sólo se puede legitimar como un derecho penal de emergencia que rige excepcionalmente. Los preceptos penales a él correspondientes tienen por ello que ser separados estrictamente del derecho penal de ciudadanos, preferiblemente también en su presentación externa." Advierte que "el derecho penal de enemigos tiene que ser también separado del derecho penal de ciudadanos de un modo tan claro que no exista peligro alguno de que se pueda infiltrar por medio de una interpretación sistemática o por analogía o de cualquier otra forma en el derecho penal de ciudadanos". Cfr. Op. cit., pp. 322-323. Uno de los primeros autores que cuestionó en España la legitimidad del derecho penal del enemigo fue J. Silva Sánchez. Cfr. La expansión del derecho penal. Aspectos de la politica criminal en las sociedades postindustriales, 2001, p. 166. Pese a ello, parece que el autor también asume la conveniencia excepcional de esa figura, en situaciones de absoluta necesidad, subsidiariedad y eficacia, en un marco de emergencia, Ibid. Un argumento que recuerda al expuesto por Jakobs en su trabajo de 1985.

${ }^{8}$ Cfr. G. Jakobs, "Das Selbstverständnis der Strafrechtswissenschaft vor den Herausforderungen der Gegenwart”, 2000, Op. cit., pp. 49-54. En esa dirección, comenta que bajo el nombre de derecho penal también discurre el complemento de un derecho penal que es un derecho de lucha contra el enemigo. Cfr. $O p$. cit., p. 54. Al respecto, J. Schulz recela de la idea de continuidad que afirma Jakobs entre las interpretaciones del derecho penal del enemigo de 1985 y su ulterior planteamiento, porque ya no se trataría tanto de una categoría analítica. Cfr. "Die deutsche Strafrechtswissenschaft vor der Jahrtausendwende", en ZStW, n 3, 2000, p. 659. Sobre esta cuestión, recuerda C. Prittwitz que inicialmente fue el propio Jakobs quien utilizó la noción del "Derecho penal del enemigo" con la finalidad de criticar la tendencia antiliberal y bélica, para más tarde, contrariamente, justificarla en el año 1999. Cfr. "Derecho penal del enemigo: ¿análisis crítico o programa del derecho penal?", en La política criminal en Europa, 2004, pp. 112-116. Sin embargo, en opinión de B. Schünemann, el planteamiento de Jakobs se ha comportado como una bomba de espoleta retardada, puesto que la primera formulación de la categoría del derecho penal del enemigo en Francfort ya descansaba en un reconocimiento de su necesidad. Cfr. "Die deutsche Strafrechtswissenschaft nach der Jahrtausendwende", en GA, 2001, pp. 210-213. Véanse los comentarios de Callies, Naucke, Schroeder y Tiedeman, en el resumen de la reunión que realiza Gropp en ZStW 97, 1985, pp. 919ss.

${ }^{9}$ Ciertamente, dice, "el mundo puede dar miedo, y de acuerdo con una vieja costumbre, se mata al
} 
de una de sus últimas publicaciones, ${ }^{10}$ cualquier interrogante o duda sobre sus pretensiones se han disipado: por mucho que le pese, no sólo cumple el papel del mensajero que se limita a trasladar la visión objetiva de una situación. Su tesis no se contenta con la descripción de una realidad con la que se puede estar o no de acuerdo, sino que, dando un salto cualitativo, y teniendo en cuenta que descarta expresamente otra alternativa al derecho penal del enemigo, ofrece legitimación contractualista a la generalización del estado de excepción frente al enemigo. ${ }^{11}$ En este trabajo, por tanto, aclara algunas incógnitas y confiesa (sólo) determinados fundamentos filosóficos de su construcción.

El contenido de la crítica debe enfocarse no sólo a la técnica legislativa vigente, también al proceso legitimador de ese modelo del "derecho penal del enemigo" fundado en la distinción entre persona y no-persona, al que contribuye decisivamente el último Jakobs, descubriendo los fundamentos filosóficos que sustentan esa distinción. Éstos son de índole contractualista, schmittiana y estructural-funcionalista.

En primer lugar, es posible trazar un paralelismo y, a la vez, un distanciamiento, con Rousseau; se acerca a él cuando comparte la categoría "enemigo" como denominador común del que infringe el pacto social. El infractor, al no respetar el pacto, pierde la condición de persona moral, es un mero hombre que en su situación pone en peligro a los demás ciudadanos. Por ese motivo, y dado que deja de ser miembro del Estado (instituido sobre la representación de la voluntad general), ${ }^{12}$ está expuesto al derecho de guerra, a la muerte o a la exclusión. ${ }^{13}$ No debe olvidarse que para Rous-

mensajero que trae una mala noticia por lo indecoroso de su mensaje. Ninguna palabra más sobre esto". Cfr. "Derecho penal del ciudadano y derecho penal del enemigo", en Jakobs/Cancio Meliá, Derecho penal del enemigo, 2003, p. 15.

${ }^{10}$ Cfr. "Derecho penal del ciudadano y derecho penal del enemigo", En, Jakobs/Cancio Meliá, Derecho penal del enemigo, 2003.

${ }^{11}$ En uno de sus últimos trabajos, G. Jakobs admite que el Estado no tiene por qué poner en juego negligentemente su configuración y que la renuncia a instrumentos como los agentes encubiertos, las escuchas ilegales y otros similares, puede favorecer que se vacie de contenido el derecho del ciudadano a la seguridad, y "este derecho a la seguridad sólo es otra denominación del derecho al estado de vigencia real del derecho”. Cfr. “¿Terroristas como personas en derecho?”, en Derecho penal del enemigo, G. Jakobs/M.Cancio Meliá, $2^{a}$ ed., 2006, p. 75. Sin embargo, hay autores que aún se niegan a creer que éste piensa lo que realmente dice. En ese sentido, J. M. Zugaldía Espinar insiste en que Jakobs critica y deslegitima el derecho penal de enemigo y además, recalca que la distinción entre "persona" e "individuo" carece de repercusiones prácticas en el ámbito de los derechos fundamentales de la persona. Cfr. "Seguridad ciudadana y estado social de derecho...", Op. cit., p. 1132.

${ }^{12}$ Sobre la crítica en torno al concepto de voluntad general y su interpretación como voluntad racional, vid. G. W. Hegel, Lecciones sobre la historia de la filosofía III, 1981, p. 400; así como de él mismo, Principios de la filosofía del derecho, 1999, p. 372.

13 "Mediante el exilio como infractor del pacto, o mediante la muerte como enemigo público". Cfr. J. 
seau no se tiene derecho a matar sino a aquel a quien no se puede conservar sin peligro. En este sentido, afirma que "todo malhechor que al atacar el derecho social se convierte con sus fechorías en rebelde y traidor a la patria, cesa de ser miembro de ella al violar sus leyes, e incluso le hace la guerra. Entonces, la conservación del Estado es incompatible con la suya, es preciso que uno de los dos perezca, y cuando se hace morir al culpable, es menos como ciudadano que como enemigo". ${ }^{14}$

Es precisamente esa idea de exclusión, de lucha, de la guerra contra el infractor, otra señal de sintonía con la propuesta de Jakobs. No obstante, frente a Rousseau, objeta que cualquier infractor del contrato sea un enemigo que pierde, por eso, la condición de ciudadano.

Otro de los autores contractualistas referentes en la tesis de Jakobs es Fichte. Para este autor, la razón de la pérdida (o privación) de los derechos de ciudadano como consecuencia de la ruptura del contrato social -ya sea de modo intencionado o negligente- reposa en la naturaleza jurídica del sujeto, que únicamente se convierte en "hombre" mediante la interrelación social ${ }^{15}$ todos los derechos positivos que posee el ciudadano sólo los tiene a condición de que los derechos de todos los otros ciudadanos estén seguros ante él ${ }^{16}$ el individuo exige reciprocidad, el hombre sólo es hombre entre los hombres, la intersubjetividad como estado natural. ${ }^{17} \mathrm{En}$ esa construcción, el Estado (instituido igualmente sobre la representación de la voluntad general) impone a las diversas voluntades una coacción que les obliga a permanecer en un contorno limitado. ${ }^{18}$ Ante la infracción del pacto, desaparece la condición de capacidad jurídica, la integración en una sociedad de seres racionales y el individuo deja de tener derechos.

Fichte asienta así un precedente de la tesis de Luhmann basada en la persona como construcción socionormativa. En efecto, si el fin del poder del Estado reside en garantizar la seguridad recíproca de los derechos de todos ante todos, entonces, el delito excluye al sujeto de la protección del Estado; en ese caso, "el criminal se convierte en proscrito, es decir que "su seguridad está tan poco garantizada como la de un pájaro, ex lex, hors de

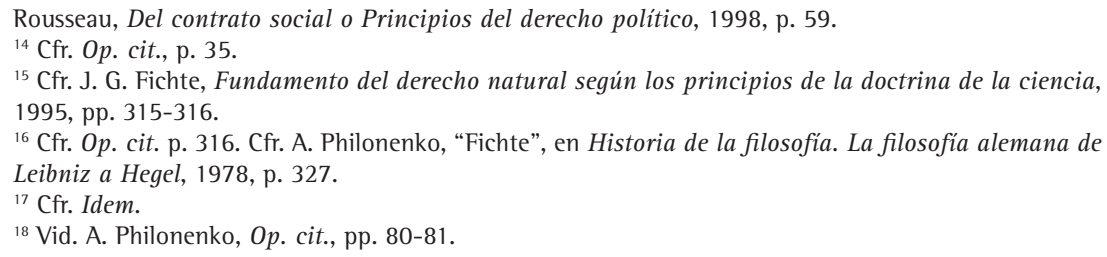


loi". ${ }^{19}$ La privación de derechos aparece, pues, como el resultado del fin de la relación jurídica entre el Estado y el individuo, la supresión del contrato. Por ese motivo, al no existir ningún deber estatal de protección del excluido, éste puede ser tratado arbitrariamente, toda vez que "el condenado es declarado ser una cosa, una cabeza de ganado" sin derecho a nada. ${ }^{20}$ Piénsese que al carecer de derechos, tampoco hay un fundamento jurídico que rechace la tortura o la muerte del excluido del Estado, pero tampoco existe un apoyo jurídico de las mismas: no se puede decir tengo el derecho $a$ ni no lo tengo. ${ }^{21}$ Es más, la ejecución del criminal por parte del Estado no tendría la consideración de castigo sino de medida de seguridad; dado que el condenado no existe para el derecho, el Estado no mata (o rescinde el contrato) en el ámbito judicial sino en el policial. ${ }^{22}$

Sin embargo Fichte, a diferencia de Rousseau, no engloba a todos los criminales en la categoría de enemigos, antes bien, distingue entre las diversas modalidades delictivas. Así, en casos en los que se ataca mediatamente al Estado, o cuando no se comprometa la seguridad pública, admite la posibilidad de crear un medio de expiación distinto a la exclusión absoluta del Estado, recurrir a lo que él denomina "contrato de expiación" que sustituye a la sanción de exclusión (por ejemplo, mediante el trabajo de reparación) cuyo cumplimiento devuelve al sujeto la condición de ciudadano. ${ }^{23}$

Tales testimonios aparecerán más tarde en Jakobs como símbolos de la metamorfosis de un derecho penal a un derecho policial y se verán reflejados en la concepción neofuncionalista del enemigo.

Pese a su proximidad, Jakobs ha manifestado una cierta desvinculación respecto de los postulados de Rousseau y Fichte; ${ }^{24}$ objeta, sobre todo, que la distinción en ellos "entre el ciudadano y su derecho [...] y el injusto del enemigo [...] es demasiado abstracta". ${ }^{25}$ En esa dirección, considera inaceptable que todo delincuente sea tratado como enemigo, y, por ende, que

${ }^{19}$ Cfr. J. G. Fichte, $O p$. cit., p. 316.

${ }^{20}$ Cfr. Op. cit., p. 331. En realidad éste es el planteamiento sostenido por la actual administración norteamericana respecto a los detenidos en Guantánamo.

${ }^{21}$ Cfr. Op. cit., p. 331.

${ }^{22}$ Fichte llega a proponer que el criminal sea estrangulado o decapitado en secreto en la prisión, pues "mediante la ruptura del contrato, él está cívicamente muerto y borrado del recuerdo de los ciudadanos. Lo que se hace al hombre físico nada importa al ciudadano". Cfr. Op. cit., p. 332.

${ }^{23}$ Mientras que en los crímenes contra el Estado, así, a través de la rebelión y la alta traición, la exclusión es absolutamente necesaria. Cfr. $O p$. cit., pp. 323 y 325.

${ }^{24}$ G. Jakobs, "Derecho penal del ciudadano y derecho penal del enemigo", Op. cit., p. 28. No es, desde luego, evidente su distanciamiento respecto de la posición de Fichte.

${ }^{25}$ Cfr. "Derecho penal del ciudadano...", Op. cit., p. 28. 
pierda el estatus de persona -“su situación dentro del derecho"-, porque ello imposibilitaría, por un lado, alcanzar la reinserción social y, por otro, obtener el deber de reparación de éste. ${ }^{26}$

Pues bien, es cierto que Jakobs, del que puede decirse lo que Madame de Staël expresó respecto de Rousseau ("no dijo nada nuevo, pero lo incendió todo"), no atiende exactamente al contractualismo de los autores aludidos; su tesis puede enmarcarse más en el proyecto de Hobbes y Kant. A la par, es la teoría de la excepción, la dicotomía schmittiana y el estructural-funcionalismo de Luhmann lo que define indudablemente su propósito, la base de su construcción.

En primer término, puede apreciarse una notable influencia de la tesis de Hobbes que hace residir el fundamento de la metáfora contractualista en la (búsqueda o consecución de la) seguridad, el fin por el que los hombres someten su voluntad a la de otro. ${ }^{27}$ En realidad, el origen de la construcción del Estado es el miedo al regreso al estado de naturaleza en el que "cualquiera puede matar a cualquiera", ${ }^{28}$ pues ahí reina la anarquía, el sujeto se encuentra como individuo, no como ciudadano. ${ }^{29}$ Para Hobbes es precisamente esta identidad de estado de naturaleza y violencia lo que justifica el poder absoluto del soberano (con la intención de lograr un mínimo de seguridad). ${ }^{30}$

Por ello, el estado de naturaleza exige la necesidad del estado civil, en el que todos los ciudadanos están seguros de su existencia física, reina la tranquilidad, el orden, ${ }^{31}$ la protección de la propiedad..$^{32}$

El miedo, la inseguridad, sólo pueden evitarse mediante el decisionismo soberano. Por eso piensa Hobbes que el contrato por el que los hombres

\footnotetext{
${ }^{26}$ Cfr. Idem. Sin embargo, cabe recordar que Fichte establece una separación entre el contrato de expiación y reparación (al que estaría sometida la mayoría de los criminales) y la sanción de exclusión del Estado reservada para casos excepcionales de asesinato, rebelión y alta traición. Cfr. "Fundamento del derecho natural...", pp. 323 y 325.

${ }^{27}$ Cfr. T. Hobbes, De Cive, 2000, p. 124. Es la seguridad la razón por la que los sujetos ceden sus derechos a un único individuo que retiene, indica E. Bloch, en "El Estado, el poder del lobo del estado de naturaleza"; el soberano es el que mantiene el derecho de la fuerza con el fin de mantener el orden; los súbditos tienen la obligación de someterse absolutamente a todos sus mandatos. Cfr. Bloch, Derecho natural y dignidad humana, 1980, p. 48.

${ }^{28}$ Cfr. T. Hobbes, De Cive, Op. cit., p. 117. Parece que emplea el término "matar" como un signo más de la metáfora. Cfr. Y. C. Zarka, Hobbes y el pensamiento político moderno, 1997, p. 140.

${ }^{29}$ Cfr. O. Höffe, Estudios sobre teoría del derecho y la justicia, 1988, p. 11.

${ }^{30}$ Cfr. G. Agamden, Homo sacer. El poder soberano y la nuda vida, 1998, p. 51.

${ }^{31}$ C. Schmitt, El Leviathan en la teoría del Estado de Tomas Hobbes, 2003, p. 25.

${ }^{32} \mathrm{Su}$ proyecto está integrado en el contexto de la ideología burguesa, se pliega al absolutismo y a los intereses de esa clase social. Vid. G. W. Hegel, Lecciones sobre la historia de la filosofía, Op. cit., pp. 332-333. Cfr. E. Bloch, Derecho natural y dignidad humana, p. 49.
} 
acuerdan formar la sociedad no basta para producir esa seguridad: hace falta la existencia de un poder común en virtud del cual los individuos particulares sean gobernados por miedo al castigo. ${ }^{33}$ Lo que genera entonces la necesidad de fundar un poder político que permita la paz y la concordia es el estado de guerra $;^{34}$ es el temor al castigo lo que proporciona seguridad, el miedo a perder determinados valores, y no un contrato, lo que fundamenta el poder en torno al Estado. ${ }^{35}$ En realidad, con arreglo al planteamiento hobbesiano, el contrato por el que surge el Estado no es un contrato social apoyado en un acuerdo en libertad sino que irradia la sumisión y dominación. ${ }^{36}$

La concepción de Hobbes sobre el pacto social sufre alteraciones en su obra Leviatán, ${ }^{37}$ pues aquí el súbdito no está sometido al poder del soberano en virtud de una obediencia absoluta sin derechos. ${ }^{38}$ Así, si el sujeto

\footnotetext{
${ }^{33}$ Cfr. T. Hobbes, De Cive, Op. cit., p. 117. De ese modo, el señor tiene un poder supremo y puede decir de sus siervos lo mismo que de cualquier otra cosa animada o inanimada: esto es mío. $0 p$. cit., p. 158.

${ }^{34}$ Lo que Hobbes denomina estado de guerra en realidad es la condición por la que los hombres establecen relaciones de enemistad por el temor a la muerte, la rivalidad y la búsqueda de la gloria. Cfr. Y. C. Zarka, Hobbes y el pensamiento político moderno, p. 62. Pero, como ya ocurriera con Rousseau, puede refutarse el argumento de Hobbes basado en una guerra entre hombres cuando sólo es posible la guerra entre estados.

${ }^{35}$ Vid. T. Hobbes, De Cive, pp. 124-125; del mismo, Leviatán o la materia, forma y poder de un Estado eclesiástico y civil, 1999, p. 167.

${ }^{36}$ Sostiene G. Agamden que el fundamento del poder soberano en Hobbes no debe buscarse en la libre cesión por parte de los súbditos de su derecho natural, sino, más bien, en la conservación, por parte del soberano, de su derecho natural de hacer cualquier cosa a cualquiera, que se presenta ahora como derecho de castigar. Cfr. Homo sacer. El poder soberano y la nuda vida, p. 138. El decisionismo soberano le lleva a admitir que el príncipe no está obligado ni a la observancia de sus propias leyes ni al juramento hecho a sí mismo, exceptuándose las leyes divina y natural y las justas convenciones y tratados en que participan. Cfr. J. Bodino, Los seis libros de la república, 1973, pp. 53, 59. Por ello, E. Bloch considera que la construcción de Hobbes elogia al Estado justamente como un monstruo, señalando, además, la indudable lealtad del autor a la dictadura, una lealtad que priva al soberano de todo carácter sacral y lo expone como el último lobo. Cfr. Derecho natural y dignidad humana, $\mathrm{p}$. 48. En torno a la ilegitimidad de la razón de Estado dictada por la emergencia hobbesiana -el estado de guerra justifica políticamente la ruptura de las reglas del juego-. Cfr. L. Ferrajoli, Derecho y razón. Teoría del garantismo penal, 1995, pp. 829ss.

${ }^{37}$ Cfr. Leviatán o la materia, forma y poder de un Estado eclesiástico y civil, p. 157. Se interpreta que el poder soberano puede lograrse por fuerza natural -adquisición- o por institución, es decir, cuando los hombres acuerdan someterse voluntariamente a algún hombre o asamblea de hombres. Cfr. Op. cit., p. 157.

${ }^{38}$ Vid. Y. C. Zarka, Hobbes y el pensamiento político moderno, pp. 63 y 70. Como se ha puesto de relieve, a la primera concepción (De Cive) responde la idea de la subordinación de la voluntad privada del súbdito a la voluntad general, interpretada no como voluntad de todos sino exclusivamente del regente, quien no sólo no es responsable ante los individuos sino que todos tienen el deber de obedecerle. Vid. G. W. Hegel, Lecciones sobre la historia de la filosofía, p. 334. Al desplazar el sometimiento del individuo, no a la voluntad general sino a la voluntad del monarca, se genera, según Hegel, un estado de perfecto despotismo frente al estado legal en el que no debe acatarse la arbitrariedad de uno sólo sino la voluntad general como estado racional determinado por las leyes.
} 
rehúsa la cooperación o se opone a decisiones ya adoptadas, ${ }^{39}$ entonces "será abandonado a su situación natural de guerra, como estaba antes, y podrá ser destruido por cualquier hombre sin que éste incurra en injusticia"40 (en el estado de naturaleza no hay injusticia ya que no hay nada que humanamente pueda llamarse injusto). Por ese motivo, el daño infligido al enemigo no puede calificarse de castigo, pues si éste no está sujeto a la ley, no puede transgredirla ni ser objeto de transgresiones; sólo puede ser objeto de actos de hostilidad. ${ }^{41}$ De ahí emerge el doble modelo del derecho penal: un derecho de súbditos a los que se les aplica las penas establecidas legalmente (el castigo contractual) y un derecho de enemigos, cuyas sanciones no pueden calificarse como castigo. ${ }^{42}$ Porque los castigos que están estipulados por la ley sólo son aplicables a los súbditos, no a los enemigos (sometidos a actos de hostilidad); y tales son quienes, habiendo actuado con anterioridad como súbditos, se rebelan deliberadamente con hechos o con palabras y niegan el poder soberano -la autoridad del representante del Estado-, pues al negar su sujeción a ley, el individuo niega también el castigo que legalmente ha sido determinado y, por tanto, sufrirá las consecuencias que se derivan de ser un enemigo del Estado, es decir, estará a merced de la voluntad del representante. ${ }^{43}$ Estos argumentos aparecen reiteradamente expuestos en la tesis de Jakobs. ${ }^{44}$

En suma, la conducta del que conscientemente se opone a la autoridad del Estado se integra en la esfera de los actos de hostilidad y no en el ámbito del derecho penal, estando sometido al derecho de guerra como enemigo del Estado. ${ }^{45} \mathrm{Al}$ no aceptar la subordinación, se autoexcluye del Estado y recupera el derecho natural (estado de naturaleza, sin reglas). Ahora bien:

\footnotetext{
${ }^{39} \mathrm{Si}$ el sujeto entró voluntariamente en el pacto, tácitamente dio su consentimiento para reconocer la voluntad de la mayoría. Cfr. T. Hobbes, Leviatán, p. 161 (tanto si pertenece a una congregación de votantes, como si no, ya se le consultase o no, deberá someterse a los decretos de los congregados). Op. cit., p. 162

${ }^{40} \mathrm{Cfr}$. Idem.

${ }^{41}$ Cfr. T. Hobbes, Leviatán, p. 268.

${ }^{42}$ De otra opinión, C. Pérez del Valle interpreta que el derecho penal del enemigo en Hobbes no implica en principio "la reacción de un poder estatal total frente a los discrepantes -frente a los enemigos del poder estatal totalitario-, tan sólo que quienes no asumen el estado civil han de ser tratados con las reglas del estado de naturaleza, en el que la enemistad de uno contra otro es consustancial". Cfr. "Sobre los orígenes del Derecho penal del enemigo". Algunas reflexiones en torno a Hobbes y Rousseau”, p. 607.

${ }^{43}$ Cfr. T. Hobbes, Leviatán, p. 268. A su vez, la lucha contra la rebeldía, el enemigo, siempre logra un efecto preventivo general de obediencia en los demás ciudadanos. Cfr. Y. C. Zarka, Hobbes y el pensamiento político moderno, p. 147.

${ }^{44}$ Cfr. G. Jakobs, "Derecho penal del ciudadano...", Op. cit., p. 32.

${ }^{45}$ Como ya ocurriera con Rousseau (Del contrato social..., pp. 33, 34), puede refutarse el argumento de Hobbes basado en una guerra entre hombres cuando sólo es posible la guerra entre estados.
} 
si el acto de hostilidad se deriva de la relación entre Estado y enemigo en el estado de naturaleza, y el súbdito -ciudadano- cede al soberano todos sus derechos sin límites, ¿cómo puede diferenciarse entonces entre pena y acto de hostilidad?, si el infractor pierde la condición de ciudadano, ¿cuál sería objetivamente la diferencia con Rousseau y Fichte? El soberano puede reaccionar mediante un acto hostil frente a un enemigo actual o potencial así como frente a un ciudadano; en éste último caso, cabrá sostener que ese acto sería moralmente incorrecto aunque ciertamente no ilegal, al no estar el soberano sometido a leyes positivas. Por tanto, parece que el contrato social no le concede a Hobbes una fundamentación razonable del ius puniendi. ${ }^{46}$

Otro de los apoyos de la construcción del derecho penal del enemigo de Jakobs, es el modelo universalista de Kant que asienta la exclusión del enemigo en la idea de instauración y (obligación de) pertenencia a una Constitución civil que garantice no regresar al estado de naturaleza, entendido éste como un estado de guerra sometido a una constante amenaza de hostilidades, una situación de inseguridad. ${ }^{47}$ Sin embargo, se contradice Kant cuando, alejándose del planteamiento sustentado en Sobre la paz perpetua, introduce la figura del enemigo injusto. En ese sentido, es conocida su teoría de que los estados se enfrentan en estado de naturaleza como personas morales en igualdad de derechos; cada uno de ellos tiene el mismo derecho a la guerra. Por tanto, no puede existir enemigo injusto en el estado de naturaleza, pues el estado de naturaleza es propiamente un estado de injusticia. Pese a tal afirmación, el autor distinguirá entre el enemigo justo y el injusto, siendo éste "aquel cuya voluntad manifestada públicamente es evidencia de una máxima según la cual no sería posible un estado de paz entre los pueblos, sino que habría de eternizarse el estado de naturaleza”, el que viola los tratados públicos, quedando amenazada la libertad de todos. ${ }^{48}$ Se retrocede, así, desde una interpretación jurídica del concepto iustus hostis a un concepto casi teleológico de enemigo, hasta el punto de que

${ }^{46}$ Cfr. Y. C. Zarka, Hobbes y el pensamiento politico moderno, pp. 269-270.

${ }^{47}$ Cfr. E. Kant, Sobre la paz perpetua, 2002, pp. 14 y 30. Siguiendo este planteamiento, G. Jakobs señala que no puede participar de los beneficios del concepto de persona el individuo "que no admite ser obligado a entrar en un estado de ciudadanía”. Cfr. "Derecho penal del ciudadano...", Op. cit., p. 40. Lo que se explica, dice, porque "el estado de naturaleza es un estado de ausencia de normas, es decir de libertad excesiva tanto como de lucha excesiva. Quien gana la guerra determina lo que es la norma, y quien pierde ha de someterse a esa determinación”, $O p$. cit., p. 41. Utiliza, en realidad, un argumento de C. Schmitt (Vid. El concepto de lo politico, 2002, pp. 74-75).

${ }^{48} \mathrm{Vid}$. E. Kant, Rechtslehre, 11, párrafos 57-61. Lo sorprendente y también contradictorio con arreglo a esta conclusión es que Kant considere que no deben repartirse las tierras de los enemigos injustos. 
resulta imposible distinguir entre enemigo y criminal, entre enemigo justo e injusto, entre el enemigo con derechos y el enemigo sin derechos. ${ }^{49}$

En su última consecuencia, la identificación entre enemigo y criminal debería eliminar, asimismo, las barreras que Kant establece para el vencedor justo cuando no está dispuesto a admitir que desaparezca un Estado o que un pueblo sea privado de su poder constitutivo. Se revela, señala Schmitt, que Kant no es jurista pues coloca al lado del iustus hostis al enemigo injusto que tiene un efecto más profundo que la guerra justa y la causa justa..$^{50}$ Por otro lado, al contemplar a los hombres y estados como ciudadanos de un Estado universal de la humanidad, Kant justifica como necesaria la intervención e injerencia en asuntos de otros estados. ${ }^{51}$ Por eso, aun cuando, en un principio, ningún Estado debe inmiscuirse por la fuerza en la constitución y gobierno de otro, esto no resulta aplicable en el supuesto de que el Estado se divida en dos partes a consecuencia de disensiones internas y cada una de las partes represente un Estado particular con la pretensión de ser el todo. La injerencia en ese momento estaría justificada porque la actuación tendría lugar en la anarquía del estado de naturaleza. ${ }^{52}$

En síntesis, la tesis de Jakobs pretende delimitar la frontera entre dos estructuras jurídicas ideales que conviven entrelazadas, ${ }^{53} \mathrm{el}$ derecho penal de ciudadanos y el derecho penal de enemigos, de modo que en el primer modelo se incluyan los infractores del pacto que no persisten en ello, manteniendo el estatus de persona, y, en el segundo, los que se desvían por principio, perdiendo esa consideración normativa. ${ }^{54}$ Como puede apreciarse, en relación con dicho objetivo, tampoco los postulados de Hobbes ni de Kant - con los que Jakobs se reconoce más cercano- $-^{55}$ ofrecen una delimitación suficientemente satisfactoria entre el delincuente-enemigo y el delincuente-persona.

${ }^{49}$ Cfr. C. Schmitt, El nomos de la tierra en el derecho de gentes del Jus publicum europeaum, 1979, p. 198.

${ }^{50}$ Ibid., p. 201.

${ }^{51}$ Asi supone que "una guerra preventiva contra un enemigo semejante sería aún más que una guerra justa: sería una cruzada, pues no nos enfrentamos a un simple criminal, sino a un enemigo injusto, al eternizador del estado de naturaleza”. Cfr. El nomos de la tierra..., p. 198.

${ }^{52}$ Cfr. E. Kant, Sobre la paz perpetua, p. 9. Sin embargo, dice Kant, mientras esa lucha interna no se haya decidido, la injerencia de potencias extranjeras sería una violación de los derechos de un pueblo independiente que combate una enfermedad interna; sería incluso un escándalo y pondría en peligro la autonomía de todos los estados.

${ }^{53}$ Cfr. G. Jakobs, "Derecho penal del ciudadano...", Op. cit., p. 21.

${ }^{54}$ Ibid., p. 32.

${ }^{55}$ Ibid., pp. 28ss. 
Curiosamente, es la teoría de la excepción y la dicotomía schmittiana (junto al estructural-funcionalismo de Luhmann que posteriormente analizaremos), lo que define el propósito de Jakobs, la auténtica base de su construcción. Las últimas ideas de Jakobs sobre el derecho penal y procesal del enemigo están estrechamente ligadas al concepto de lo político de C. Schmitt pese a que expresamente no aparezca citado por él. A mi juicio, carece de explicación el olvido del que, sin duda, es uno de los referentes, si no el más importante, de la construcción del derecho penal del enemigo.

Frente a la interpretación kantiana que dificulta distinguir entre enemigo y criminal, C. Schmitt propone que el concepto de enemigo pueda adoptar forma jurídica y dejar de ser algo que ha de ser aniquilado. ${ }^{56}$ Así, distingue entre el extranjero como enemigo colectivo legítimo (hostis) ${ }^{57} \mathrm{y}$ el enemigo interior ilegitimo -el bandido, rebelde o pirata-, promotor de la subversión, que es objeto de persecución penal y a quien es necesario eliminar para preservar el orden del Estado. ${ }^{58}$ Con ello, el soberano estatal se convierte en portador de la nueva ordenación del espacio dentro de su territorio delimitado y cerrado y tiene la posibilidad de superar la guerra civil por medio de la decisión soberana. En efecto, Schmitt, siguiendo a Hobbes, ${ }^{59}$ sostiene que el Estado produce en su interior una pacificación completa, procura la paz, la seguridad, el orden, generando así una situación normal que "constituye el presupuesto necesario para que las normas jurídicas puedan tener vigencia en general, ya que toda norma presupone una situación normal y ninguna norma puede tener vigencia en una situación totalmente anómala por referencia a ella”. ${ }^{60}$ A través de estos postulados, lo que Schmitt pretende evitar, en última instancia, no es la guerra sino la pérdida de lo político, el fundamento de la existencia política de un pueblo, que se instituye mediante la dicotomía amigo/ene-

${ }_{56}$ Con ello se hace posible concretar un tratado de paz con el vencido. Así pues, el derecho europeo de gentes consiguió el acotamiento de la guerra con ayuda del concepto de Estado. Cfr. C. Schmitt, El nomos de la tierra en el derecho de gentes del Jus publicum europeaum, p. 160.

${ }^{57}$ Con la intención de que su concepto de enemigo no se confunda con una interpretación psicologista, C. Schmitt recomienda que se traduzca el término Feind por hostis y no por inimicus. Hostis simboliza aquello con lo que tenemos un enfrentamiento público, mientras que inimicus queda restringido a una situación de odio. Cfr. una interpretación similar en R. Mate, Memoria de Auschwitz. Actualidad moral y politica, 2003, p. 81.

${ }^{58}$ Cfr. C. Schmitt, El nomos de la tierra..., pp. 175-176. Vid. E. Balibar, Nosotros ¿ciudadanos de Europa?, 2003, p. 103.

${ }^{59}$ En el prólogo al trabajo El Leviathan en la teoría del Estado de Tomas Hobbes, 2003, p. 1, C. Schmitt reconoce la influencia que esta obra supuso en todo su trabajo.

${ }^{60}$ Cfr. C. Schmitt, El concepto de lo político, 2002, p. 75. Véase este mismo argumento en Jakobs, “Derecho penal del ciudadano...", op. cit., pp. 32, 37 y 47. 
migo ${ }^{61}$ la distinción entre la política interior y exterior. Por ese motivo, el Estado puede definir al "enemigo interior"; ${ }^{62}$ al mismo tiempo, y por la misma razón, considera necesario mantener una política interior pacificada jurídica y conjuntamente, e intervenciones bélicas frente al exterior; en ese proyecto, la lucha exterior contra el enemigo permite la pacificación de los conflictos internos. Sólo de esta forma, es posible procurar el control de los enemigos internos con estrategias de intervención militar frente a enemigos externos. ${ }^{63}$

Dado que la guerra sólo es lucha armada entre soberanos estatales y puede corresponder al concepto de iustus hostis, ${ }^{64}$ la guerra "privada" (hombre contra hombre) es calificada de no-guerra. Un planteamiento que permitiría explicar la situación de los talibanes en Guantánamo. Al ser detenidos en una situación de no-guerra entre estados, carecen de la condición de enemigos (hostis) y, en consecuencia, serían rebeldes, "combatientes ilegales", que no son tratados como prisioneros de guerra y, por tanto, no pueden beneficiarse de los derechos que les corresponden. Los talibanes en Guantánamo alcanzarian la condición de bandidos, piratas y rebeldes que no son enemigos, no son iusti hostes, sino objeto de persecución penal y de eliminación. Asimismo, el juicio a Saddam Hussein se enmarca en esa lucha en el estado de naturaleza. La creación de un

\footnotetext{
${ }^{61}$ Cfr. R. Mate, Memoria de Auschwitz..., p. 80. T. Hobbes ve en la política la protección de la vida mientras que C. Schmitt la interpreta como disponibilidad a la muerte (disposición al sacrificio de la vida). Esto es, para aquél la política es la negación de lo político y para éste tiene su origen en la dicotomía amigo/enemigo. Ibid. Dicotomía que aparece en su obra El concepto de lo político, en la que el autor se aleja del iusnaturalismo católico y se dirige claramente hacia el decisionismo soberano. Cfr. P. González Cuevas, La tradición bloqueada, 2002, p. 193. Para G. Lukács, se trataría de una vacuidad arbitraria carente de sentido científico ya que reduce todas las múltiples y complejas relaciones políticas al esquema amigo-enemigo. Cfr. El asalto a la razón, 1967, pp. 533ss. Una crítica similar recibe de J. Habermas, Cfr. "Carl Schmitt: los terrores de la autonomía”, en Identidades nacionales y postnacionales, 1989, pp. 68-70. Vid. por todos, J. A. López Garcia, "La presencia de Carl Schmitt en España”, en Estudios Políticos, $\mathrm{n}^{\circ}$ 91, 1996, pp. 143ss.

${ }^{62}$ Por esa razón, C. Schmitt afirma que si una parte del pueblo declara que ya no conoce enemigos, lo que está haciendo en realidad es ponerse del lado de los enemigos y ayudarles, pero desde luego no se cancela la distinción entre amigos y enemigos. "Si un pueblo tiene miedo de los riesgos y penalidades vinculados a la existencia política, lo que ocurrirá es que aparecerá otro pueblo que le exima de unos y otras, asumiendo su "protección contra los enemigos exteriores" y en consecuencia el dominio político; será entonces el protector el que determine quién es el enemigo, sobre la base del nexo externo de protección y obediencia”. Cfr. El concepto de lo político, p. 81. Esta teoría hobbesiana basada en que fuera del nexo de protección y obediencia no existe ni la legalidad ni la legitimidad racionales, pues esa relación es exigida tanto por la naturaleza humana como por el derecho divino, se repite en Jakobs, "Derecho penal del ciudadano...", op. cit., p. 32.

${ }^{63}$ Cfr. J. Habermas, La idea kantiana de la paz perpetua. Desde la distancia histórica de 200 años. La inclusión del Otro, 1999, p. 182.

${ }^{64}$ Cfr. C. Schmitt, El concepto de lo político, p. 91.
} 
tribunal ad hoc el 10 de diciembre de 2003 al margen de Naciones Unidas, la ausencia de letrado durante un año, la falta de experiencia profesional de los jueces y fiscales del caso, adiestrados por jueces estadunidenses y británicos, evidencian que el Estado se enfrenta al "tirano" fuera de la Constitución civil.

Es evidente que la separación amigo/enemigo de Schmitt, que no alude a una ficción sino a una realidad óntica distinguible, es la base de la dicotomía entre el derecho del ciudadano y el derecho del enemigo de Jakobs. ${ }^{65}$ Sin duda, éste asume el planteamiento schmittiano que atribuye al Estado el ius belli, esto es, la posibilidad de determinar quién es el enemigo y cómo combatirlo, y, en consecuencia, de disponer de la vida de las personas; ${ }^{66}$ en este sentido, Schmitt alude a "formas de proscripción, destierro, ostracismo, de poner fuera de la ley, en una palabra, de declarar a alguien enemigo dentro del Estado; formas automáticas o de eficacia regulada judicialmente por leyes especiales, formas abiertas u ocultas en circunloquios oficiales" ${ }^{67}$ Igualmente coincide con el autor, cuando, como él, Jakobs defiende la lucha contra el enemigo en los márgenes del estado civil, fuera de la Constitución civil, esto es, en el estado de naturaleza: si la Constitución, como expresión del orden social, es atacada, la lucha debe ubicarse fuera de la propia Constitución y el derecho a través de las armas

\footnotetext{
${ }^{65}$ En la misma dirección, J. de Lucas alude a la teoría política y constitucional de C. Schmitt como una de las fuentes de la tesis de Jakobs. Cfr. "Nuevas estrategias de estigmatización. El derecho frente a los inmigrantes”, en Mutaciones de Leviatán. Legitimación de los nuevos modelos penales, 2005, pp. 210-211.

${ }^{66}$ Cfr. C. Schmitt, El concepto de lo político, pp. 74-75. Los conceptos de amigo, enemigo y lucha se mantienen en conexión con la posibilidad real de matar físicamente (p. 63). Véase esa idea en Jakobs, "Derecho penal del ciudadano...", Op. cit., pp. 38-39. Por otra parte, C. Schmitt, como también hace G. Jakobs, parte del principio de que la calificación de "enemigo" no tiene que ser peyorativa, "el enemigo político no necesita ser moralmente malo, ni estéticamente feo..." Simplemente es el otro, el extraño. Cfr. El concepto de lo político, p. 57; de modo parecido, Jakobs, "Derecho penal del ciudadano...", $O p$. cit., p. 22. Cree J. Habermas que C. Schmitt es inconsecuente cuando mantiene la asimetría entre una situación jurídica pacificada hacia dentro y un belicismo hacia fuera. A su juicio: "Deja al arbitrio de los que tienen el poder la criminalización de los adversarios políticos como enemigos de una guerra civil. Dado que en esta zona límite de las relaciones internas se relajan los controles del estado de derecho, se produce el efecto que Schmitt teme como consecuencia de una pacificación de las relaciones interestatales: la introducción de categorias morales en las acciones políticas protegidas jurídicamente y la estilización del adversario como agente del mal." Cfr. Habermas, La idea kantiana de la paz perpetua, p. 186. Afirma este autor que, de hecho, se ha producido en la escena internacional una moralización directa de la política tan perniciosa como el enfrentamiento del gobierno con sus enemigos internos. Se ha moralizado, esto es, se ha enjuiciado según criterios de "lo bueno" y "lo malo" y luego se ha criminalizado, esto es, se ha juzgado según criterios de lo lícito y lo ilícito sin que se haya cumplido el momento decisivo, que Schmitt suprime, de los presupuestos jurídicos para una instancia judicial imparcial y una ejecución de la pena que resulte neutral. Op. cit., pp. 186-187.

${ }^{67} \mathrm{Cfr}$. C. Schmitt, El concepto de lo político, p. 75. En términos similares se expresa G. Jakobs, "Derecho penal del ciudadano...”, Op. cit., p. 42.
} 
-la guerra civil-, siendo, entonces, preciso el rechazo físico e incluso el combate. $^{68}$

En el contexto del enemigo, Jakobs sugiere que la lucha debe ubicarse fuera del marco constitucional ya que, en esos casos, no puede afirmarse que exista un estado real de vigencia del derecho, sino tan sólo un postulado de realización: esto es, rige el estado de naturaleza y ahí no hay reglas. ${ }^{69}$ Esto le conduce a cuestionar la reacción penal frente al terrorista (alude expresamente al atentado del 11 de septiembre de 2001) que rechaza por principio la legitimidad del ordenamiento jurídico y persigue la destrucción del orden; dado que el terrorista no garantiza una expectativa de conducta personal, si no se quiere privar al derecho penal del ciudadano de "sus cualidades vinculadas a la noción de estado de derecho", debería llamarse derecho penal del enemigo a lo que "hay que hacer contra los terroristas si no se quiere sucumbir"; ${ }^{70}$ en consecuencia, se haga lo que se haga en la lucha contra el terrorismo, no hay nada ilegítimo. ${ }^{71}$ Y no cabe duda que así lo mantiene: afirma que contra los autores de vulneraciones de los derechos humanos, "quienes por su parte tampoco ofrecen una seguridad suficiente de ser personas", hay que concebir "todo lo que sea necesario para asegurar el ámbito "comunitario-legal" -"la creación de un orden del derecho a mantener un orden"-, pues no se trata de personas culpables sino de "enemigos peligrosos"; ${ }^{72}$ por ello objeta el que se mantenga posteriormente con el infractor, una vez capturado, "la ficción de la vigencia universal de los derechos humanos", esto es, un uso del derecho de ciudadanos, una devolución ficticia de su condición de persona. ${ }^{73}$ Resulta inquietante esta última reflexión de Jakobs sobre la vigencia global de los derechos humanos ante los supuestos de vulneraciones terroristas; en cierta medida, nos recuerda a las imputaciones que C. Schmitt realizaba

\footnotetext{
${ }^{68}$ Ibid., pp. 76 y 78. Idea que se repite continuamente en G. Jakobs, "Derecho penal del ciudadano...", Op. cit., pp. 41, 42, 45, 49 y 55. En el derecho del enemigo, subraya metafóricamente, sólo es factible la coacción física, hasta llegar a la guerra. $0 p$. cit., p. 33. Eso sí, puede limitarse a no excluir al enemigo de todos los derechos y a una contención del Estado para facilitar un hipotético acuerdo de paz. En su obra Teoría del partisano, Schmitt indica que éste necesita, para no llegar a confundirse con el criminal, una legitimación basada en la legalidad cuando el Estado converse con él. Cfr. Teoría del partisano, 1966, pp. 115ss.

${ }^{69}$ Cfr. "Derecho penal del ciudadano...", p. 54.

${ }^{70} \mathrm{Op}$. cit., pp. 41-42. Por ello, cree que la introducción de líneas y fragmentos de derecho penal del enemigo en el derecho penal del ciudadano es un mal desde la perspectiva del estado de derecho. Cfr. Op. cit., pp. 48 y 50.

${ }^{71}$ Op. cit., pp. 50, 56.

${ }^{72}$ Op. cit., p. 54.

${ }^{73}$ Op. cit., pp. 54-55.
} 
a la teoría de los derechos humanos y al concepto de humanidad, en el sentido de que la cláusula de los crímenes contra la humanidad era sólo la más general de las cláusulas para el exterminio del enemigo. ${ }^{74}$

Si éstos son antecedentes del modelo penal de Jakobs, la columna vertebral del modelo sistémico aplicado a la concepción del "enemigo" radica en la propia noción de persona elaborada por Luhmann, ${ }^{75}$ un concepto que se funda en la comunicación social y no en la mera individualidad, pues no pretende expresar la singularidad individual de la naturaleza concreta del sujeto humano, sino que retiene su sentido de una idea colectiva. ${ }^{76}$ En la creación de esta figura, Luhmann deslinda los sistemas psíquicos (concien(ias) ${ }^{77}$ del concepto de persona, pues "Con la personalidad de lo que se trata es de la regulación de la interacción social", ${ }^{78}$ mecanismo que fluye cuando los individuos se perciben y seleccionan comportamientos en función de esa percepción. Por ello, la definición de persona aparece inevitablemente unida al problema de los sistemas sociales en los que se condiciona la realización de los partícipes como personas a la correspondencia de los demás respecto a cada uno de ellos. ${ }^{79}$ Si la persona y sus características surgen de la doble contingencia, esto es, de la elección entre lo que es actual y posible y, a su vez, lo que es posible por otros caminos y no necesario, la selección de un camino excluirá las demás posibilidades. ${ }^{80}$

Si bien las sociedades modernas se fundamentan, según Luhmann, en los principios de igualdad y libertad deducidos de la teoría del contrato social - libertad para la aceptación del contrato social e igualdad de todos los que forman parte del mismo-, las diferencias se originan a partir del uso de la libertad de los concretos sistemas parciales y, particularmente,

${ }^{74}$ Cfr. J. Habermas, La idea kantiana de la paz perpetua..., p. 181.

${ }^{75}$ Así lo considera también J. de Lucas. Cfr. "Nuevas estrategias de estigmatización...”, Op. cit., p. 210. Sin embargo, L. Gracia Martín no parece muy conforme con la identificación que realizo entre la concepción del enemigo en Jakobs y el concepto de no-persona en Luhmann. Cfr. "Consideraciones críticas sobre el actualmente denominado derecho penal del enemigo"”, RECPC, 07-02 (2005), p. 23; del mismo autor, El horizonte del finalismo y el derecho penal del enemigo, Valencia, 2005, p. 177.

${ }^{76}$ Cfr. N. Luhmann, Complejidad y modernidad de la unidad a la diferencia (La forma persona), 1998, pp. 231-237. Esto lo explica el autor al distinguir al individuo de la "identidad social", esto es, "el yo dado para sí mismo sólo fragmentaria y situativamente de aquel otro normal, redondeado, que ha de satisfacer expectativas sociales especialmente referidas al mantenimiento de la identidad de uno consigo mismo". Cfr. $O p$. cit., p. 231. Vid. una exposición detallada de la construcción de este autor en Portilla Contreras, "Los excesos del formalismo jurídico neofuncionalista en el normativismo del derecho penal”, en Homenaje al profesor Dr. Gonzalo Rodríguez Mourullo, 2005, pp. 861ss.

${ }^{77}$ Vid. N. Luhmann, “Die autopoiesis des Bewusstseins", Soziale Welt, n 36, 1985, pp. 402-446. Cfr. G.

Corsie, E., Esposito, C. Baraldi, Glosario sobre la teoría social de Niklas Luhmann, 1996, pp. 150ss.

${ }^{78}$ Cfr. N. Luhmann, Complejidad y modernidad..., p. 236.

${ }^{79}$ Op. cit., pp. 239, 243-244.

${ }^{80}$ Cfr. N. Luhmann, Soziale Systeme. Grundriss einer allgemeinen Theorie, 1984, p. 571. 
de la idea de organización formal. Las expectativas dirigidas hacia las personas se basan, ante todo, en el contraste entre pasado y futuro centrado en la biografía. ${ }^{81}$ Por ello, no todos pueden participar en los sistemas de modo integral pues va a depender de las formas de organización de la comunicación. De modo paralelo, esta afirmación expresa la separación entre la igualdad formal en el ámbito del sistema parcial y la desigualdad real en el espacio de organización formal. Es evidente que la exclusión de los subsistemas puede llevar al individuo a ser irrelevante como persona $;^{82}$ esto puede ocurrir, bien por la exclusión de la organización formal, o por la autoexclusión del contrato social que impide la participación en el sistema parcial. El concepto del individuo como no-persona es, por tanto, una de las consecuencias de los excesos del formalismo jurídico.

El modelo penal y procesal propuesto por Jakobs se apoya precisamente en la teoría de sistemas orientada a la teoría de la comunicación. En su opinión, la persona existe únicamente desde una visión normativa, una construcción social, ${ }^{83}$ de tal modo que serán la vinculación normativa y la necesidad social las que determinen la fundamentación de los intereses empíricos de los individuos. ${ }^{84}$

Esta visión normativa de la persona recuerda, asimismo, el carácter exterior y formal de dicha noción reivindicado por Kelsen al afirmar que, producto de una construcción jurídica, la persona sólo puede existir como sistema de derechos y deberes - "la unidad personificada de las normas jurídicas que atribuyen deberes y derechos al mismo hombre"-. "En este sentido, la llamada persona física es una persona jurídica." ${ }^{{ }^{55}}$ Las conexiones entre Kelsen, C. Schmitt y Jakobs son evidentes: la persona sólo puede existir socialmente como persona jurídico-política, como "sistema de derechos y deberes" (Kelsen), como un sujeto de un ordenamiento político (C. Schmitt), o como una construcción normativa de la interrelación social

\footnotetext{
${ }^{81}$ Vid. N. Luhmann, "Wie ist soziale Ordnung möglich?”, en Gesellschaftsstruktur und Semantik, n 2, 1981, pp. 208ss. Cfr. G. Corsie, E. Esposito, C. Baraldi, Op. cit., p. 93.

82 "Una persona puede ser no-persona, sin que por ello deje de ser hombre, individuo." Cfr. N. Luhmann, Complejidad..., p. 237; del mismo, La realidad de los medios de masas, 2000, p. 50.

${ }^{83}$ La persona existe en función de su relación social, "la relación con al menos otro individuo no se basa solamente en las propias preferencias, sino que se define mediante al menos una regla independiente de tales preferencias, de tal manera que el otro puede invocar esa regla. Tal regla es una norma social en sentido estricto: si se infringe, ello significa elegir una configuración del mundo de cuya toma en consideración había sido precisamente exonerado el otro". De ese modo, resuelve que "el individuo emprende algo que sólo tiene sentido si no se encuentra solo en el mundo". Cfr. G. Jakobs, Sociedad, norma y persona en una teoría de un derecho penal funcional, 1996, p. 79.

${ }^{84}$ Cfr. G. Jakobs, Sociedad, norma y persona..., pp. 79- 81.

${ }^{85}$ Cfr. H. Kelsen, La teoría pura del derecho, 1975, p. 198.
} 
(Jakobs). En todos los casos, el concepto de persona no es un concepto ontológico sino que siempre depende del derecho vigente. ${ }^{86}$

En efecto, para Jakobs, es el complejo normativo el que define las características jurídicas de la persona ${ }^{87}$ porque -explica- "ante el otro se constituye el sujeto a través de la vinculación a la norma y necesita la propia autorreferencia del otro para que éste, a su vez, se convierta en sujeto" ${ }^{88}$ Posteriormente, en torno a la formación de "todo orden personal", ha resaltado la importancia de los "deberes de contribuir al mantenimiento del grupo que existe a través del orden" ${ }^{89}$ de lo que se deriva que el rango de persona se determina en función de los deberes sociales. Si esto es así, el estatus de persona se interrumpirá cuando el individuo no realice o no pueda cumplir su deber frente al grupo: ${ }^{90}$ en los casos de ausencia de participación en los deberes respecto de los demás, el individuo deja de ser persona porque "aquel al que no se necesita se le excluye de la obra común, y cuando ha entendido esto sólo le queda la retirada hacia la mera individualidad". ${ }^{11}$

La integración en el proceso sistémico de semejante conformación normativa de persona es lo que ha respaldado la separación del derecho penal en función de la valoración entre las acciones de las personas y las de las no-personas (enemigos), y, con ello, la conversión del derecho del "enemigo" en un derecho de guerra; ${ }^{92}$ aquí el sujeto - por su posición, forma de vida, o pertenencia a una organización- se transforma en no-persona por haber abandonado el derecho, generalmente no de forma incidental sino duradera, por lo que no garantiza la más mínima seguridad cognitiva (de conducirse conforme a la norma), déficit que expresa a través de su conducta.

Concretamente, se incluye en el concepto de enemigo a individuos por la realización de comportamientos con una dimensión incidental -delitos sexuales-, o por la peligrosidad de los delitos habituales del parágrafo 20 StGB. A este grupo se suman aquellos que por su pertenencia a una organi-

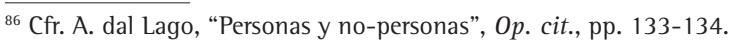

${ }^{87}$ Cfr. G. Jakobs, Sociedad, norma y persona en una teoría de un derecho penal funcional, 1996, p. 85. No todo ser humano es persona jurídico-penal. Cfr. del mismo Sobre la normativización de la dogmática jurídico-penal, pp. 20-21, 2003.

${ }^{88}$ Vid. Sociedad, norma y persona...p. 80.

${ }^{89}$ Cfr. G. Jakobs, "Sobre la génesis de la obligación jurídica”, en Doxa, no 23, 2000, p. 342.

${ }^{90}$ Cfr. G. Jakobs, “Sobre la génesis de la obligación jurídica”, Op. cit., p. 343.

${ }^{91} \mathrm{Op}$. cit., p. 348.

${ }^{92}$ En el concepto de derecho penal del enemigo se adopta el término "guerra". Cfr. G. Jakobs, "Das Selbstverständnis der Strafrechtswissenschaft”..., Op. cit., p. 53. 
zación -criminalidad organizada, en especial, tráfico de drogas- presumiblemente puedan mantenerse alejados de modo duradero del derecho. ${ }^{93}$

El fundamento de esta tesis reside en que quien actúa como persona debe, a la sazón, ofrecer una garantía cognitiva; en caso de rehusar expresamente a ofrecer ese mínimo de seguridad, entonces el derecho penal se ve obligado a modificar sus contenidos habituales; así, se pasa de la respuesta social ante la acción de uno de sus miembros a la reacción contra el enemigo para evitar riesgos futuros. ${ }^{94}$ Jakobs ha subrayado últimamente que "si ya no existe la expectativa seria [...] de un comportamiento personal -determinado por derechos y deberes-, la persona degenera hasta convertirse en un mero postulado, y en su lugar aparece el individuo interpretado cognitivamente. Ello significa [...] la aparición del individuo peligroso, el enemigo". ${ }^{95}$

De similares fundamentos parten los seguidores de la concepción del derecho penal del enemigo de Jakobs, ${ }^{96}$ que aplican, asimismo, la terminología conceptual, la teoría sistémica de Luhmann al derecho penal. Dado que ésta no emplea criterio alguno para cuestionar la legitimidad de un Ordenamiento, la existencia de una norma contará de modo inmediato con el respaldo de la teoría sistémica al identificar legitimidad con legalidad en la producción del derecho. Por esta razón, no es de extrañar que, confirmado el desarrollo de los elementos de un derecho penal del enemigo, dicha teoría sirva de base dogmática en la legitimación del mismo. No obstante, cabe cuestionar la rigurosa adaptación de los planteamientos del derecho penal del enemigo de Jakobs y sus seguidores a los postulados de la teoría sistémica, especialmente, en algunas de las propuestas de la pre-

\footnotetext{
${ }^{93}$ Cfr. G. Jakobs, "Das Selbstverständnis der Strafrechtswissenschaft...” Op. cit., p. 52; del mismo, "Derecho penal del ciudadano...", op cit., pp. 39-40.

${ }^{94}$ Cfr. G. Jakobs, "Das Selbstverständnis der Strafrechtswissenschaft", $O p$. cit., p. 51. Vid., del mismo, Sobre la normativización de la dogmática jurídico-penal, p. 54.

${ }_{95}$ Cfr. G. Jakobs, "Derecho penal del ciudadano...", Op. cit., p. 14. Últimamente, Jakobs ha vuelto a insistir en este argumento y lo ha aplicado de nuevo al terrorismo. Subraya que "todo aquel que presta fidelidad al ordenamiento jurídico con cierta fiabilidad tiene derecho a ser tratado como persona", y quien no lleve a cabo esta prestación, será heteroadministrado, lo que significa que no será tratado como persona. Cfr. “¿Terroristas como personas en derecho?”, pp. 68-69. En estos casos de autoexclusión en los que no se presta fidelidad al ordenamiento jurídico, según Jakobs, no cabe emplear un discurso libre sino la coacción, lo que resulta incompatible, entiende, con la definición de persona. Contra esta clase de sujetos debe utilizarse, afirma, bien una custodia de seguridad o una pena privativa de libertad que garantice el aseguramiento, es decir que sea extensa. 0 p. cit., p. 70.

${ }^{96}$ Véanse, en este contexto, H. H. Lesch, "Hörfalle und kein Ende Zur Verwertbarkeit von selbstbelastenden Angaben des Beschuldigten in der Untersuchungshaft", en GA, n 147, 2000, pp. 355-362; B. Müssig, "Beweisverbote im Legitimationszusammenhang von Strafrechtstheorie und Strafverfahren", en GA, 1999, pp. 121ss.; M. Pawlik, "Verdeckte Ermittlungen und das Schweigerecht des Beschuldigten zu den Anwendungsgrenzen der 136, abs. 1 satz 2 und 136 a) StPO”, en GA, 1998, pp. 379-381.
} 
vención general positiva que se han identificado como inequivocamente sistémicas, y que no lo son, o, al menos, no pueden reconocerse como tales a la luz del último Luhmann -el derecho como sistema autopoiético-. La interpretación que hacen aquellos autores de los conceptos "no-persona" y "exclusión" de Luhmann puede incurrir en la contradicción de considerar, nuevamente, al sujeto como conciencia autónoma y no como mero objeto de un sistema. Como ha advertido con acierto García Amado, resulta incoherente seguir la teoría de sistemas afirmando que cada sujeto individual lo inventa cada sistema social, y, a la vez, sostener que el sujeto penal existe y es constitutivamente libre. En efecto, las discordancias aludidas se exteriorizan a la hora del examen de la conciencia del individuo, de la culpabilidad, de la legitimidad del sistema penal o de la pena, puesto que tratan como real al sujeto cuando, para la tesis sistémica, sólo es una ficción instrumental de los sistemas jurídicos actuales. ${ }^{97}$ En consecuencia, se está propugnando un cambio absoluto en los paradigmas del derecho procesal-penal debido, no tanto a la existencia de un peligro real que tiene su origen en las organizaciones criminales, sino al desarrollo sesgado de la teoría sistémica y sus principios filosóficos - precedentes aristotélicos y contractualistas. $^{98}$

Únicamente de esta manera, puede llegar a entenderse que Lesch defienda que el sujeto no actúa en derecho como individuo, como sistema psico-psíquico de identidad humana, sino especialmente como persona (construcción normativa). Sin embargo, como la persona elige para sí misma la libre administración de un círculo organizativo, igualmente, como reverso de este derecho, puede llegar a ser excluida si opta por separarse del derecho, manteniendo así una conexión entre la libertad de organización y la respuesta; libertad sin responsabilidad no es realmente una liber-

${ }_{97}$ Cfr. J. A. García Amado, “¿Dogmática penal sistémica? Sobre la influencia de Luhmann en la teoría penal”, en Doxa, n²3, 2000, p. 233. Tales incongruencias no son sino "el resultado de ser radicales en las premisas pero no querer serlo en las consecuencias" (p. 249). Cfr. también Prieto Navarro, "Teoría de sistemas, funciones del derecho y control social. Perspectivas e imposibilidades para la dogmática penal”, en Doxa, n² 23, 2000, pp. 267-285, 288. Así, olvida que en derecho la persona sólo se define a través de un sistema de reglas basadas en la responsabilidad individual. Cfr. B. Schünemann, "Die deutsche Strafrechtswissenschaft nach der Jahrtausendwende”, Op. cit., p. 212. Según este autor, el lenguaje del derecho penal del enemigo representa, en el mejor de los casos, una metáfora engañosa, Ibíd. Acerca de ello, también, J. Schulz, "Die deutsche Strafrechtswissenschaft...", Op. cit., p. 663.

${ }^{98}$ Vid. G. Jakobs, "Das Selbstverständnis der Strafrechtswissenschaft...”, Op. cit., pp. 47-56; H. H. Lesch, "Hörfalle und kein Ende Zur Verwertbarkeit von selbstbelastenden Angaben des Beschuldigten in der Untersuchungshaft", Op. cit., p. 355; M. Pawlik, "Verdeckte Ermittlungen und das Schweigerecht des Beschuldigten...”, Op. cit., p. 378. Cfr. una crítica a esta posición en H. Schneider, "Bellum Justum gegen den Feind im Inneren?", Op. cit., pp. 504-505. 
tad personal, es más una arbitrariedad subjetiva; persona, en la dirección social del concepto de Luhmann, es el garante de su propia identidad en las conductas sociales. ${ }^{99}$ Bajo similares fundamentos, Müssig mantiene que la perspectiva individual está condicionada por un sentido de dependencia subjetiva y el modelo de orientación también depende de la conducta de otros. ${ }^{100}$ Asimismo, Pawlik apoya su tesis en las diferencias entre individuo y persona defendidas por Jakobs; en su opinión, el sujeto adquiere la condición jurídica de persona exclusivamente a través de la posición jurídica que se le reconoce al ser portador de derechos y obligaciones, ${ }^{101}$ un estatus que no se mantiene a toda costa. ${ }^{102}$

Pues bien, basándose en un estatus normativo de persona, Jakobs ha planteado la necesidad de distinguir dos modelos de intervención frente al delincuente: uno para "ciudadanos" - sujeto a un proceso penal garantístico-, y otro para "enemigos". Si en el primero se espera del ciudadano infractor cierta fidelidad a la norma y una mínima seguridad cognitiva, en la falta de ésta se apoya el segundo $;{ }^{103}$ si en el derecho penal del ciudadano la pena mantiene la vigencia de la norma, se dirige al restablecimiento de la expectativa defraudada, pues, el ciudadano, en cuanto tal, es llamado a compensar el daño causado a la misma, el derecho penal del enemigo combate peligros. En este nuevo formato, que modifica sustancialmente la estructura de la culpabilidad y la pena, el sujeto se transforma en una emanación de peligro, un riesgo para la seguridad, y, en virtud de ello, en enemigo del ordenamiento jurídico. Esa potencial peligrosidad se conjura mediante una legislación penal preventiva que sólo atiende a la

\footnotetext{
${ }^{99}$ Cfr. H. H. Lesch, "Hörfalle und kein Ende...", Op. cit., p. 362; del mismo, "Inquisition und rechtliches Gehör in der Beschuldigtenvernehmung”, en ZGS, n 111, 1999, p. 637.

${ }^{100}$ Para este autor, la misión del derecho penal está unida a la teoría de la prevención general positiva y al significado social de las normas, mientras que la función del derecho depende de la estructura de la sociedad. Cfr. B. Müssig, "Beweisverbote im Legitimationszusammenhang von Strafrechtstheorie und Strafverfahren”, $O p$. cit., pp. 121ss. En su función social, las normas exigen un cambio de la perspectiva individual a la social porque lo que interesa no es la acción individual sino la comunicación como práctica social: la autorreferencia del proceso de comunicación como sistema social. Las acciones de los individuos son, bajo el punto de vista del contacto social, interacciones, dibujan una dependencia común comunicativa. Desde este ángulo, las normas - como esperanza de la estructura social- constituyen la fundamentación de la autodescripción y el modelo de organización de cada sistema social; construyen los fundamentos comunes de un contexto social y se ocupan de las situaciones interactivas; edifican la estructura en el proceso de comunicación y las formas -la figura de cada sistema comunicativo. Cfr. $O p$. cit., p. 121. Así interpretadas, las normas jurídicas formalizan el símbolo de la estructura del sistema social de comunicación, definen la figura de la sociedad.

${ }^{101}$ Cfr. M. Pawlik, "Verdeckte Ermittlungen und das Schweigerecht des Beschuldigten...”, Op. cit., p. 379. Se basa en la obra de Jakobs, Norm, Person, Gesellschaft, 1997, pp. 29ss.

${ }^{102}$ Cfr. M. Pawlik, "Verdeckte Ermittlungen..." Op. cit., p. 381.

${ }^{103}$ Cfr. G. Jakobs, “Derecho penal del ciudadano...”, Op. cit., pp. 25-26 y 36-38.
} 
eliminación del riesgo generado por el "individuo peligroso" a través de medidas de seguridad. ${ }^{104}$ En otras palabras, se afirma que no existen otras alternativas al derecho penal del enemigo porque el Ordenamiento jurídico no puede integrar a sujetos que no reúnen las mínimas garantías cognitivas imprescindibles para actuar como personas, ${ }^{105}$ porque, en definitiva, "quien no presta una seguridad cognitiva suficiente de un comportamiento personal, no sólo no puede esperar ser tratado aún como persona, sino que el Estado no debe tratarlo ya como persona, ya que de lo contrario vulneraría el derecho a la seguridad de las demás personas”. ${ }^{106}$

Proteger la seguridad cognitiva se convierte en la finalidad principal del derecho penal del enemigo, esto es, la conservación del ordenamiento de las personas frente a todo lo que provoca un grave trastorno interno social, por lo que serán eliminadas aquellas condiciones ambientales que no ofrecen las garantías cognitivas mínimas y que impiden en la práctica comportarse como personas. ${ }^{107}$ En esa misma dirección, Lesch ha insistido en que el derecho penal de la culpabilidad debe tornarse en protección de la seguridad del Estado ante una modificación excepcional de las circunstancias. Precisamente, en esa situación límite, el denominado "derecho penal cívico" de la culpabilidad, dice, debe sustituirse por la razón de Estado. ${ }^{108}$ De todos modos, este autor no considera que en ese derecho penal cívico deba calificarse la teoría de la pena como prevención general positiva. Por el contrario, lo define como una teoría funcional retributiva y compensadora de la culpabilidad, que supera la oposición entre la fundamentación absoluta y la relativa, en donde fundamento y fin de la pena se unifican y adquieren no sólo una dimensión dialéctico-hegeliana, sino también práctico-utilitarista. ${ }^{109}$ La clave de este pensamiento reside en que el temor a la destrucción de la sociedad civil exige una metamorfosis del

${ }^{104}$ Cfr. G. Jakobs, “Derecho penal del ciudadano...", Op. cit., pp. 24-25. Ya en el marco más concreto del terrorismo, Jakobs asegura que el derecho penal tiene más bien el cometido de garantizar seguridad que el de mantener la vigencia del ordenamiento jurídico, como cabe inferir del fin de la pena y de los tipos penales correspondientes. Cfr. “¿Terroristas como personas en derecho?”, p. 72.

${ }^{105}$ Cfr. G. Jakobs, “Das Selbstverständnis der Strafrechtswissenschaft...” Op. cit., pp. 50-52.

${ }^{106}$ Cfr. G. Jakobs, "Derecho penal del ciudadano...”, Op. cit., p. 47.

${ }^{107}$ Cfr. G. Jakobs, "Das Selbstverständnis der Strafrechtswissenschaft...”, Op. cit., p. 53.

${ }^{108}$ Cfr. H. H. Lesch, La función de la pena, 1999, p. 46.

${ }^{109} \mathrm{Ibid}$., p. 50. Contra las reminiscencias hegelianas de este argumento hay que recordar la censura de E. Bloch a la teoria retributiva de Hegel que justifica la pena como negación de la negación. De ninguna manera -insistía Bloch - se elimina más concretamente la existencia del delito que por la eliminación de las condiciones que lo hacen nacer y que lo harán siempre nacer. Un marxismo en sentido propio sería, por eso, en tanto que tal teoría penal radical, más aún, la más radical y, a la vez, la más cordial: porque el marxismo mata la matriz social de la injusticia. Cfr. Derecho natural y dignidad humana, Op. cit., p. 269. 
derecho penal cívico, no siendo posible formular juicios de culpabilidad individual-especial, sino, por el contrario, hay que redefinir a la persona de esa nueva sociedad post-civil y los derechos de los que disfruta. ${ }^{110}$

Como se ha podido comprobar al hilo de este análisis del derecho penal-procesal del enemigo, tanto Jakobs como algunos de sus discípulos han pretendido ofrecer legitimación al violento reingreso de la teoría del estado de excepción schmittiana, del concepto de enemigo injusto y la guerra justa como manifestación primigenia de un derecho penal que, de ese modo, se militariza. Se justifica así la acción bélica preventiva que se plantea en el estado de naturaleza, un escenario en el que todo es válido contra el enemigo ${ }^{111}$ en la búsqueda de la seguridad cognitiva de los "ciudadanos". En definitiva, se brinda la cobertura perfecta al regreso del decisionismo soberano.

Volver al Índice >>

\footnotetext{
${ }^{110}$ H. H. Lesch, La función de la pena, p. 52.

${ }^{111}$ Cfr. R. Harzer, “Staaten im globalen Naturzustand?”, en Festschrift für Klaus Lüderssen, 2002, p. 481.
} 